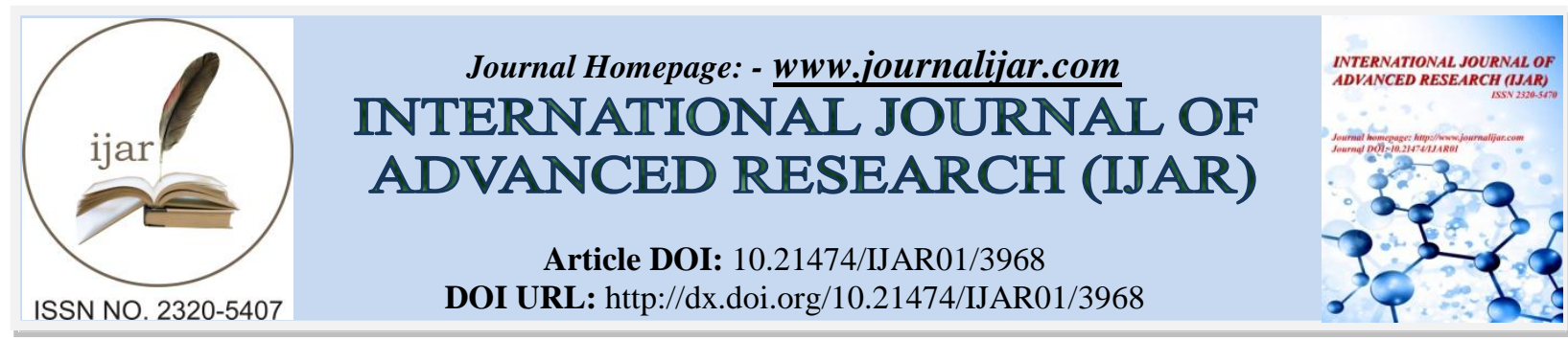

RESEARCH ARTICLE

\title{
EFFECTIVE MANAGEMENT OF DISASTER ISSUES: ROLE OF INTER-REGIONAL CO-OPERATION.
}

\author{
Dr Gulshan Wani ${ }^{1}$, Dr Geeta Rani ${ }^{2}$, and Iqra Rasheed ${ }^{3}$. \\ 1. Sr. Assistant Professor, Department of Education, University of Kashmir, Srinagar. \\ 2. Assistant Professor, Mewar University, Rajasthan. \\ 3. Research Student, Mewar University, Rajasthan.
}

\section{Manuscript Info}

Manuscript History

Received: 17 February 2017

Final Accepted: 05 March 2017

Published: April 2017

Key words:-

Disaster Management, Inter-regional

Cooperation, Challenges

\section{Abstract}

Life on this blue planet has progressed tremendously over centuries however under the shadow of huge natural threats \& hazards which have got further complicated with the inclusion of manmade disasters. Although with the scientific advancements, humans have been able to manage efficiently some of the potential disasters, but still the quantum of threats $\mathrm{s}$ too huge. This has made the global community to think and act together for promotion of "Global Culture of Prevention". Resourceful developed world has been successful in reducing to a greater extent the human loss arising from such onslaughts, but the under-developed world continues to suffer badly. Under the global initiative number of facilities are available for both developed and under developed countries but since it requires very strong resource base and as these disasters are not limited to any particular regions/states therefore there is an imperative need for regional cooperation to face challenges efficiently. Asia-Pacific is one of the worst hit regions. This article therefore attempts to highlight the need for regional co-operation under global initiatives, to ensure that economic gains achieved are not marred by the disasters

Copy Right, IJAR, 2017,. All rights reserved.

\section{Introduction:-}

In the recent past the quantum of disasters has increased tremendously. Earlier there were mostly natural disasters such as floods, hurricanes, earthquakes, volcanic eruptions, heat weaves, draughts, extreme weather events etc and a few man made ones like wars, rebellions, commotions etc. Now other types of disasters of higher magnitude have also got added up to the ugly list like the environmental emergencies caused due to technological, Industrial or transportation activities, forest fires, etc as a result of excessive human interferences into the nature, ever increasing/ excessive human waste due to speedy urbanization/changing life styles, nuclear holocausts/ explosions, pandemic diseases, Complex emergencies like break-down of authority etc.

In the last decade of the last century, floods accounted for more than two thirds of people affected by natural disasters. However they were less deadly than many other types of disasters, accounting for $1.5 \%$ of deaths. While earthquakes accounted for 30\% of damages and caused $9 \%$ of deaths of all the disasters due to nature. In contrast famines have killed $42 \%$ but caused just $4 \%$ damages. In the first decade of the current century, 4777 natural 
disasters occurred, killing more than 8,80,000 people. In addition they affected the property, health and jobs of about 2 billion people and caused economic loss of $\$ 685$ billion to the world economy ${ }^{1}$.

Losses as a consequence of humanly induced disasters besides wars, rebellions, terrorist acts etc, for instance due to miss-handling, miss-use, .miss-management etc are equally terrifying. Some of the major accidents include, methyl isocyanine gas leak at Bhopal (India) in 1984, Switzerland Sandoz Warehouse fire in Basel in 1989 ; three nuclear accidents including Three Miles Island in US in1979, and at Chernobyl in 1986 (Which forced many countries to abandon their vital nuclear programmes). Floods of 1993 of Midwestern rivers of the state of Lawa in USA caused a loss of $\$ 123$ millions to business, $\$ 700$ to public buildings, one billion $\$$ to agriculture sector besides damaging 21200 homes. 9/11 attacks of 2001 on World Trade Centre, \& Pentagon with three plane crashes resulting in about 3000 deaths alone and about 25 billion damages to the properties. Hurricane Katrina of 2005 that struck Florida USA with wind speed of 140 miles an hour, made havoc in the costal areas ${ }^{2}$.

'These disasters are neither limited to any specific geographic zone nor linked to any specific community. However whenever and wherever they occur they have huge adverse socio-economic impacts. For example food crises of 1980s in Africa not only devastated economies of many countries of that continent but also due to large scale migrations effected many other adjacent countries of Asia and Latin America. As such these calamities have huge social, political, economic , cultural and scientific linkages... ${ }^{3}$.

\section{Disasters in Asia and pacific:-}

About $75 \%$ of the world's major natural disasters in the last three decades of the last century occurred in the Asia and the Pacific regions of the world, which is mostly consisting of poverty ridden developing countries. The impact of the natural disasters has been very sever with more than 1.4 million people killed, almost 400 million affected and US\$438 million properties damaged ${ }^{4}$.

China experienced more than 300 natural disasters with 3,11,000 deaths. India with more than 300 disasters recorded 1,20,000 deaths. Indonesia experienced more than 200 disasters with more than 15,000 lives lost. Bangladesh experienced 181 events of disasters with 2,50,000 people killed. ${ }^{5}$.

\section{Global Initiatives:-}

Given the severity of losses inflicted, systematic Study of Disaster Management started soon after world war first, as number of issues sprang with regard to eruption and prevention of disasters. Since there were all round developments in the scientific field, efforts started to find scientific solutions to these problems. In some cases of disaster, humans have been able to know in advance likelihood of occurring of such events and means to save the mankind from bad effects and mitigate losses to the humans from such disasters.

The strong scientific back-up and the good disaster management has produced encouraging results. According to an estimate , during 1990-2000 about six lack deaths took place due to major disasters out of which just $1 \%$ were in developed countries and $99 \%$ in the developing countries. Before 1950s the situation was quite different and at least $30 \%$ deaths took place in developed countries and $70 \%$ in the developing countries. ${ }^{6}$.

“On an average 22.5 people die per reported disaster in highly developed countries, 145 die per disaster in countries with medium human development, and 1052 people die per disaster in countries with low levels of development. ${ }^{7 "}$

\section{Need and Justification:-}

Post disaster analysis of many disasters have indicated that the losses to people and property could have been very low if proper advance planning, and management could have been done. Many disaster events especially in the

${ }^{1}$ Ref Disaster vulnerability and Management in Global Prospective Chapter viii, by B C Bose.

${ }^{2}$ Ref Disaster vulnerability and Management in Global Prospective Chapter viii, by B C Bose.

${ }^{3}$ Ref Disaster Management Chapter ist (Through the new millennium) edited by Ayaz Ahmad.

${ }^{4}$ Ref Disaster vulnerability and Management in Global Prospective Chapter viii, by B C Bose.

5. Ref ist chapter of Disaster \& Hazard Management By P Nambooderipad

${ }^{6}$ Ref Disaster Management Chapter ist (Through the new millennium) edited by Ayaz Ahmad

${ }^{7}$ Ref Chapter ist of Disaster Vulnerability and Management in Global Perspective by Bose B C. 
fields of chemical, nuclear power sectors, besides earthquakes, floods tsunamis etc have impacts that transcend natural boundaries. This has compelled the world community to think and act jointly.

The large difference in loss is a consequence of good analysis, proper planning, effective disaster management aiming at prevention /mitigation methods and technology and techniques adopted by the developed countries with the result that losses are eliminated where possible and minimised in case of sever acts of nature. In other words advanced countries make proper planning well in advance to handle such challenges as and when they occur.

Given the severity of the issue, UNO, the world body, recognised the complex and ever increasing problem as a global threat to the mankind and has been pursuing a consistent policy to handle the problems.

Towards the end of 20th century it was felt that the importance of an effective Disaster Management Programme can also be seen from the comparative losses of developed countries viz-a-viz developing countries. For instances in case of Latur(India) earthquake of 1993 left more than 10,000 people dead besides billions of Rs property loss. As against this a similar earthquake of Los-Angles (USA) 22years earlier to this event, left just 55 dead. The new disaster management policy not only making plans for post -disaster, it also lays stress on pre- disaster management so that people are saved not only from the on-going threats but also from threats of future.

In view of above, it was decided by the world body to declare the last decade of 20th century, International Decade for Natural Disaster Reduction (IDNDR)8. In this regard UN Assembly adopted its resolution no 44/236 in 1989 and formally decided following main objectives of IDNDR.

The objective of the decade was to reduce through concentrated international action especially in developing countries, the loss of life, property damage and social and economic disruption caused by natural disasters.

In 2005 a global plan for natural disaster risk reduction called Hyogo Framework was adopted by 168 countries of the world. This document provides guide- lines for achieving disaster resilience for vulnerable communities. The document acknowledged that, the humanitarian community does a remarkable job in responding to disasters. but the most important task in the medium and long term is to strengthen and broaden programmes which reduce the number and cost of disasters in the first place. Whilst we should continue to improve and strengthen our response capacity we need to engage in working together to build a "Global Culture of Prevention."

\section{Role of Regional Co-Operation:-}

" The Indian sub-continent in general and India in particular is the region facing maximum number of natural disasters. The phenomenon of occurrences of earthquakes is also very common in this region due to continuous movement of the Indian plate and the striking European plat, as well as the location of the youngest mountain chain in the form of Himalayas. Thus the earthquakes are a regular feature of the sub-continent and may result in sever damage of life and property, ${ }^{10}$,

Besides being under the grip of sever earthquake, the brunt of other natural disasters like floods, draughts, cyclones tsunamis, are also borne by almost all the countries of the region, India Pakistan Nepal, Bangladesh, Bhutan, SriLanka, Afghanistan besides adjacent China, Russia etc. This has been adversely affecting the socio economic scenario of the region where many of the countries have also been facing political strife continuously. Despite having huge natural resource base the region is one of the poorly developing areas of the world.

\section{The Indian Scenario:-}

India which is sharing physical boundaries with number of countries Bangladesh, Nepal, Russian, China, Pakistan, Afghanistan etc is also sharing geological boundaries with many of them. It shares as such most of natural disasters e g floods, earthquakes, typhoons etc with many of them. This is therefore one of the fields of co-operation amongst these countries.

\footnotetext{
${ }^{8}$ Ref chapter 10 Disaster Management Through the New Millennium edited by Ayaz Ahmad.

${ }^{9}$ Ref document of Hyogo Framework for Action 2005-2015: I S D R .

${ }^{10}$ Ref Disaster Management Chapter ist (Through the new millennium) edited by Ayaz Ahmad.
} 
Earthquakes, floods, draughts, cyclones, accidents etc are major types of disaster phenomenon occurring in south Asia. India is a large country of this region and is as such bearing major share of these hazards.

Because of the large geographical size of the country extending between latitudes 8.4 and 37.6 north and longitudes of 68.7 and 97.25 east; India often faces natural hazards like floods, cyclones ,earthquakes and draughts occurring frequently in different parts of the country.

India is vulnerable, in varying degrees, to a large number of natural as well as man-made disasters. 58.6 per cent of the landmass is prone to earthquakes of moderate to very high intensity; over 40 million hectares (12 per cent of land) is prone to floods and river erosion; of the 7,516 km long coastline, close to 5,700 km is prone to cyclones and tsunamis; 68 per cent of the cultivable area is vulnerable to drought and hilly areas are at risk from landslides and avalanches. Vulnerability to disasters /emergencies of Chemical, Biological, Radiological and Nuclear (CBRN) origin also exists. Heightened vulnerabilities to disaster risks can be related to expanding population, urbanisation and industrialisation, development within high-risk zones, environmental degradation and climate change ${ }^{11}$ :

\section{Managing Disasters is Strategic:-}

The essence of the disaster management is to follow a long-range policy to handle huge unforeseen hazards, risks and threats with limited resources and in crises situations to minimise losses. This is therefore specifically a field of strategic management .

Peter Druker the world renowned management expert while commenting on management capabilities states,:-

"The one certainty about the times ahead, the times which managers will have to work and perform, is that there will be turbulent times, and in the turbulent times the first task of the management is to make sure of the institutional capacity for survival, to make sure of its structural strength,......"12

Keeping in view the un-ending adverse behaviour of the natural disasters getting further loaded by the man-made disasters, and the tacit difference between the developed and the developing countries in terms of the losses being suffered, there is an urgent need of close co-operation on regional basis of these countries, ( besides being part of global initiatives) so that mitigation measures against disasters are effective and result oriented . A glaring example is that of the European Union, where despite many of the member countries being resourceful and scientifically advanced, have realised that their joint efforts will enable them to mange efficiently the disaster threats of the future and as such are pooling their resources to combat the disasters.

\section{Role of Educational Institutions in strengthening the community resilience:- \\ Public Education and training system:-}

One of the important objective of Disaster Management Programme is to ensure adequate awareness of the different stakeholders including the affected people about different potential hazards, plans in hand for minimising the losses. The disasters when strike, undo totally the progress achieved by the community. The community not only looses its assets base but also its capacity for revival is affected adversely. Low level of knowledge and awareness results in poor resilience of events of disaster. Steps are required to be taken by different agencies and the public for public safety. Preparedness of concerned communities in case of eventualities is to be ensured. The concerned local Govts. Should introduce training programmes for preparing people in case of eventualities., so that people may not get un-reasonably disturbed/pan icy when such disasters happen.

\section{Disaster Awareness through educational institutions:-}

The efforts of the state and its agencies concerned with the welfare of the state can become more and more meaningful once the requisite level of awareness is brought at community level on disaster management. This in turn will ensure not only minimum possible loss in case of any eventuality but also a manageable environment under such emergency circumstances.

Proper education of the eventualities opens the horizons of the target classes. Instead of being apprehensive such educated classes are able to develop into groups and teams which are well aware of the threats and means to address

${ }^{11}$ Ref policy document on Disaster Management 2009 GOI

${ }^{12}$ Ref Chapter Ist of Managing in Turbulent Times by Peter Druker. 
such threats with least losses. They become one of the most dependable groups under emergency conditions. They help in development of community disaster resilience by preparing people to face the challenges, to withstand shocks/ stresses of natural and manmade disasters, climate changes, massive urbanisation, deforestation etc which is much needed under such circumstances. A significant change in the community thinking is the real base for a better change.

\section{Educational Research in the applied field of disaster resilience:-}

The proper description \& for creation of requisite level of awareness and resilience on disaster management is an essential requirement. A systematic study of these issues as such justifies an Educational Research.

\section{Conclusion:-}

Efforts to promote economic develop ment is of paramount importance and a world wide phenomena. But these efforts are futile and deceptive if the governments do not take due care of the looming threats caused by technological, environmental and natural disasters. The responsible agencies must not be insensitive to such situations by adopting Ostrich approach. Instead every effort is to be made for promotion of a safety culture and safe climate......."

Support is provided under IDNDR (International Decade for Natural Disaster Reduction)t Programme towards mobilising regional co-operation for minimising the adverse consequences of natural disasters Besides UNO, other agencies like ADB and World Bank etc are working out and supporting co-ordination efforts on regional basis as well for disaster prevention. Some of the Asian countries have embanked on some effective plans. Although some beginning has been made but the task is to be carried forward under the spirit of close co-operation amongst the countries of south Asia, to safeguard the region for a prosperous. 